\title{
Increasing cumulative exposure to volatile anesthetic agents is associated with poorer neurodevelopmental outcomes in children with hypoplastic left heart syndrome
}

\author{
Laura K. Diaz, MD, ${ }^{\mathrm{a}}$ J. William Gaynor, MD, ${ }^{\mathrm{b}}$ Shannon J. Koh, BA, ${ }^{\mathrm{b}}$ Richard F. Ittenbach, PhD, \\ Marsha Gerdes, PhD, ${ }^{\mathrm{d}}$ Judy C. Bernbaum, MD, ${ }^{\mathrm{d}}$ Elaine H. Zackai, MD, ${ }^{\mathrm{d}}$ Robert R. Clancy, MD, ${ }^{\mathrm{d}}$ \\ Mohamed A. Rehman, MD, ${ }^{a}$ Jeffrey W. Pennington, BS, ${ }^{\mathrm{e}}$ Nancy Burnham, MSN, ${ }^{\mathrm{b}}$ Thomas L. Spray, MD, ${ }^{\mathrm{b}}$ \\ and Susan C. Nicolson, MD
}

\begin{abstract}
Objectives: Despite improved survival in children with hypoplastic left heart syndrome (HLHS), significant concern persists regarding their neurodevelopmental (ND) outcomes. Previous studies have identified patient factors, such as prematurity and genetic syndromes, to be associated with worse ND outcomes. However, no consistent relationships have been identified among modifiable management factors, including cardiopulmonary bypass strategies, and ND outcomes after cardiac surgery in infancy. Studies in immature animals, including primates, have demonstrated neurodegeneration and apoptosis in the brain after certain levels and extended durations of anesthetic exposure. Retrospective human studies have also suggested relationships between adverse ND effects and anesthetic exposure.
\end{abstract}

Methods: Cumulative minimum alveolar concentration hours (MAC-hrs) of exposure to volatile anesthetic agents (VAA) (desflurane, halothane, isoflurane, and sevoflurane) were collected from an anesthetic database and medical record review for 96 patients with HLHS or variants. ND testing was performed between ages 4 and 5 years, including full-scale IQ, verbal IQ, performance IQ, and processing speed. Four generalized linear modes were hypothesized a priori and tested using a Gaussian (normal) distribution with an identity link.

Results: Cumulative VAA exposure ranged from 0 to 35.3 MAC-hrs (median 7.5 hours). Using specified covariates identified previously as significant predictors of ND outcomes, statistically significant relationships were identified between total MAC-hrs exposure and worse full-scale IQ and verbal IQ scores $(P$ 's $<.05)$ alone and after adjusting for relevant covariates.

Conclusions: Increased cumulative MAC-hrs exposure to VAA is associated with worse ND outcomes in certain domains in children with HLHS and variants. (J Thorac Cardiovasc Surg 2016;152:482-9)

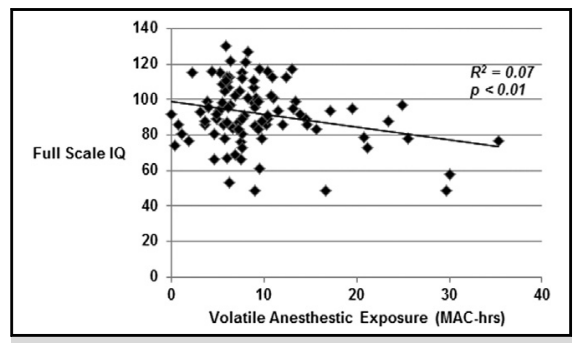

Increasing exposure to volatile anesthetic agents is associated with lower full-scale $I Q$.

\section{Central Message}

This study shows that greater exposure to volatile anesthetic agents is correlated with worse neurodevelopmental outcomes for patients with hypoplastic left heart syndrome.

\section{Perspective}

Studies in immature animals have documented neurotoxic effects of common anesthetic agents. Studies in children have shown associations between anesthetic exposure and increased likelihood of developmental disabilities. This study shows that in children with hypoplastic left heart syndrome, increasing exposure to volatile anesthetic agents (VAAs) is associated with worse neurodevelopmental outcomes, suggesting that VAA exposure may be a modifiable risk factor.

See Editorial Commentary page 490.
From the Departments of ${ }^{a}$ Anesthesia and Critical Care Medicine, and ${ }^{\mathrm{d}}$ Pediatrics, ${ }^{\mathrm{b}}$ Division of Pediatric Cardiothoracic Surgery, and ${ }^{\mathrm{e}}$ Center for Biomedical Informatics, The Children's Hospital of Philadelphia, Perelman School of Medicine at The University of Pennsylvania, Philadelphia, $\mathrm{Pa}$; and ${ }^{\mathrm{c}}$ Division of Biostatistics and Epidemiology, Cincinnati Children's Medical Center, University of Cincinnati School of Medicine, Cincinnati, Ohio.

This research was supported by a grant from the Fannie E. Rippel Foundation; American Heart Association National Grant-in-Aid (9950480N); Grant HL071834 from the National Institutes of Health; support from The Cardiac Center at The Children's Hospital of Philadelphia, the Alice Langdon Warner Endowed Chair in Pediatric Cardiothoracic Surgery and the Daniel M. Tabas Endowed Chair in
Pediatric Cardiothoracic Surgery at The Children's Hospital of Philadelphia, Perelman School of Medicine at the University of Pennsylvania.

Received for publication Oct 1, 2015; revisions received March 3, 2016; accepted for publication March 17, 2016; available ahead of print May 13, 2016.

Address for reprints: J. William Gaynor, MD, Pediatric Cardiothoracic Surgery, The Children's Hospital of Philadelphia, Perelman School of Medicine at The University of Pennsylvania, 3400 Civic Center Boulevard, Ninth Floor, Main Building, Philadelphia, PA 19104 (E-mail: gaynor@email.chop.edu). $0022-5223 / \$ 36.00$

Copyright $(2016$ by The American Association for Thoracic Surgery http://dx.doi.org/10.1016/j.jtcvs.2016.03.095 


$\begin{array}{ll}\text { Abbreviations and Acronyms } \\ \text { AIMS } & \text { Anesthesia Information Management } \\ & \text { System } \\ \text { APOE } & =\text { Apolipoprotein E } \\ \text { AUC } & =\text { area-under-the-curve } \\ \text { BSID-II } & =\text { Bayley Scales of Infant Development-II } \\ \text { CHD } & =\text { congenital heart defects } \\ \text { CNS } & =\text { central nervous system } \\ \text { CPB } & =\text { cardiopulmonary bypass } \\ \text { DHCA } & =\text { deep hypothermic circulatory arrest } \\ \text { FSIQ } & =\text { full-scale IQ } \\ \text { GA } & =\text { general anesthesia } \\ \text { HC } & =\text { head circumference } \\ \text { HLHS } & =\text { hypoplastic left heart syndrome } \\ \text { ICU } & =\text { intensive care unit } \\ \text { LOS } & =\text { length of stay } \\ \text { MAC-hrs } & =\text { minimum alveolar concentration hours } \\ \text { ND } & =\text { neurodevelopmental } \\ \text { NP } & =\text { nasopharyngeal } \\ \text { PIQ } & =\text { performance IQ } \\ \text { SES } & =\text { socioeconomic status } \\ \text { VAA } & =\text { volatile anesthetic agents } \\ \text { VIQ } & =\text { verbal IQ } \\ \text { WPPSI-III } & =\text { Wechsler Preschool and Primary Scale } \\ & \text { of Intelligence, 3rd edition }\end{array}$

Scanning this QR code will take you to the article title page.

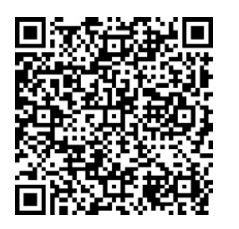

Each year approximately 10,000 neonates and infants receive general anesthesia (GA) for repair of congenital heart defects (CHDs). ${ }^{1}$ Neurodevelopmental (ND) disability occurs in many survivors, resulting in an increasing focus on prevention of adverse ND outcomes. ${ }^{2}$ There is increasing evidence of congenital and acquired preoperative central nervous system (CNS) abnormalities in infants with $\mathrm{CHD}^{3,4}$ Although some studies have implicated perioperative factors such as the use of CPB with or without deep hypothermic circulatory arrest (DHCA) and postoperative length of stay (LOS), these findings are not consistent. ${ }^{5,6}$ Instead, patient-specific factors, such as birth weight, ethnicity, and presence of a genetic syndrome, have been identified as the strongest predictors of ND outcomes in infants undergoing cardiac surgery, including those with hypoplastic left heart syndrome (HLHS). ${ }^{7,8}$
Over the past decade, studies in immature animal models, including primates, have documented neurotoxic effects on the developing brain following exposure to all anesthetic and sedative medications commonly administered to infants and children. ${ }^{9,10}$ Retrospective studies in humans have shown associations between exposure to GA in early childhood and increased likelihood of subsequent behavioral or developmental disabilities. ${ }^{11,12}$ Two recent studies have reported a potential relationship between anesthetic exposure and ND outcomes in children with CHD, but with conflicting results. ${ }^{13,14}$ Significant questions remain regarding the period of maximal vulnerability to anesthetic exposure in neonates and infants, the role specific anesthetic agents may play with respect to ND outcomes, and the effects of duration of anesthetic exposure and cumulative dose. No previous study has evaluated the potential ND effects of VAA using a homogeneous sample of preschool children with CHD with (1) repetitive exposure to anesthetic agents beginning in infancy, (2) precise quantification of the cumulative anesthetic exposure, and (3) formal evaluation of intelligence.

Our previous analysis of ND outcomes in a patient cohort with single-ventricle CHD, consisting primarily of children with HLHS, found that patient factors were more important predictors than operative management variables, but anesthetic exposure was not assessed. ${ }^{15}$ The current study was undertaken to build on these findings and evaluate the potential impact of increasing cumulative exposure to VAA, a modifiable management factor, on ND in preschool children with HLHS or variants.

\section{MATERIALS AND METHODS Sample}

This study constitutes of a subgroup analysis of patients enrolled in a prospective study evaluating the effects of apolipoprotein $\mathrm{E}$ ( $A P O E$ ) gene polymorphisms on ND outcome after cardiac surgery requiring CPB in infants 6 months of age or younger. ${ }^{16}$ Exclusion criteria for the overall study were (1) presence of multiple congenital anomalies, (2) recognized genetic or phenotypic syndrome other than chromosome 22q11 microdeletion, and (3) language other than English spoken in the home. Premature and low birth weight infants were enrolled. The current study evaluated a subgroup of infants with HLHS or variants from the time of initial anesthetic exposure to the time of ND follow-up between the ages of 4 and 5 years. All exposures to VAA at our institution during the time period from initial admission to the 4- to 5-year ND evaluation were collected retrospectively. The institutional review board at The Children's Hospital of Philadelphia approved the study and written informed consent was obtained for the primary study from a parent or guardian.

\section{Data Collection}

Demographic and preoperative factors including gestational age, birth weight and head circumference (HC), Apgar scores, and preoperative intubation were obtained from birth and hospital records. For all operative encounters, weight, age at operation, and type of operation were recorded. For cardiac surgeries using $\mathrm{CPB}$, perfusion data, including aortic cross-clamp time, CPB time, duration of DHCA, total support time (CPB time plus 
DHCA time), lowest nasopharyngeal (NP) temperature, and hematocrit after hemodilution on $\mathrm{CPB}$, were recorded.

Intraoperative exposure to VAA for all cardiac and noncardiac procedural encounters occurring in an anesthetizing location was retrieved from an Anesthesia Information Management System (AIMS) database (CompuRecord; Phillips Medical System, Andover, Mass) from the time of first anesthetic exposure to the date of ND assessment. All exposures to VAA were automatically recorded at intervals ranging from 15 seconds to 2 minutes throughout the procedure for each procedural encounter, with end-tidal exhaled concentrations used for exposure calculations. Because VAA administration frequently continued to the time of departure from the anesthetizing location, elimination assumptions were developed and used if the last recorded expired concentration of VAA in the anesthetizing location was greater than zero so as to account for total VAA exposure. End-tidal concentrations of all VAAs were assumed to drop by $50 \%$ at 5 minutes after cessation of administration. A concentration drop to 0 in 10 minutes was assumed for sevoflurane and desflurane, and a drop to 0 in 30 minutes was assumed for halothane and isoflurane. ${ }^{17-19}$ Total VAA exposure was then calculated using the area-under-the-curve (AUC) method, and subsequently converted to age-adjusted minimum alveolar concentration hours (MAC-hrs). ${ }^{20-22}$ Total VAA exposure, or cumulative MAC-hr exposure, was then determined for each patient inclusive of all known anesthetic exposures to the time of developmental assessment.

\section{Genetic Evaluation and Neurodevelopmental Examination}

Comprehensive ND evaluation of children was performed between their fourth and fifth birthdays. Growth measurements were obtained, including weight, length, and HC. Maternal education and the child's ethnicity were assessed by parental report. Familial socioeconomic status (SES) was assessed by parental report according the Hollingshead scale quintiles. ${ }^{23} \mathrm{~A}$ health history was obtained, focusing on interim illnesses, hospitalizations, neurologic events, current medications, and parental concerns regarding the child's health. Patients were examined by a genetic dysmorphologist at either 1 or 4 years of age.

Cognitive skills were assessed using the Wechsler Preschool and Primary Scale of Intelligence, 3rd edition (WPPSI-III), a standardized test of intelligence for children 3.5 to 7.0 years old that is commonly used in both clinical and research settings. It takes approximately 45 minutes to administer and yields 4 summary scores, including full-scale IQ (FSIQ), verbal IQ (VIQ), performance IQ (PIQ), and processing speed, with a mean score of 100 and standard deviation of 15 points. The WPPSI-III has been shown to have moderate to very high reliability (the coefficients for verbal, performance, processing speed, full and general language were $0.92,0.87,0.93,0.92$, and 0.90 , respectively) and validity (correlation with other cognitive tests in the positive and significant range of 0.74-0.90) in a variety of studies. ${ }^{24}$ If a child was judged to be too impaired to complete the tasks, the lowest possible score for the specific test was assigned. If unable to complete the task for other reasons, the child was excluded from the analysis for that domain.

\section{Statistical Analysis}

The aim was to test the hypothesis that, after adjusting for relevant risk factors, cumulative exposure to VAAs is inversely related to neurocognitive function in children with HLHS. This hypothesis builds on knowledge gained in a previous, related study regarding risk factors for neurocognitive function in a sample of children with single-ventricle physiology who had undergone the Fontan procedure. ${ }^{15}$ Of the 96 children in this current study, $91(95 \%)$ were included in the earlier (Fontan) study, allowing us to explicitly test the impact of VAAs on neurocognitive function in the context of previously identified risk factors, using a broader but nearly identical cohort of children with HLHS. Data analysis proceeded in 2 discrete phases: a descriptive phase and an inferential phase. Descriptive statistics were first compared for all relevant variables in the data set, across the entire sample of patients with HLHS $(n=96)$, using parametric as well as nonparametric measures of central tendency, variation, and association. Frequency counts and histograms were used for variables that were categorical or ordinal in nature.

Inferentially, 4 different generalized linear modes were hypothesized a priori and tested in accord with the overall aim of the study, using a Gaussian (normal) distribution with an identity link. Four different measures of neurocognitive development from the WPPSI-III (FSIQ, VIQ, PIQ, and processing speed) were regressed onto a cumulative measure of VAA (cumulative MAC-hrs) after adjusting for previously identified statistically significant covariates reported by Gaynor et al. ${ }^{15}$ Included covariates were as follows: $\mathrm{CPB}$, postoperative LOS, gestational age, birth weight, and lowest hematocrit on $\mathrm{CPB}$, but varied by model. For this reason, due to the close association between this sample and the one evaluated in the previous study, these covariates were hypothesized by model to be critical and statistically significant covariates with which to evaluate the impact of VAA on intelligence. All model assumptions were tested and deemed tenable before analysis, including linearity, independence, homoscedasticity, and normality of errors for 3 of the 4 models (FSIQ, VIQ, PIQ). For these models, Shapiro-Wilk tests for violations of normality were conducted and satisfied based on nonsignificant results $(P=.29-.83)$ even in the presence of a skewed MAC-hrs covariate. However, the processing speed model achieved a normal conditional error distribution test $(P>.05)$ only after transforming the outcome using a BoxCox transformation $(\wedge-1.53)$, a natural log transformation of MAC-hrs, and removal of one outlier. Criteria for statistical significance included an overall test significance at an adjusted $\alpha_{\mathrm{ADJ}}=0.015$ level to account for the correlated nature of the 4 outcomes using Turkey, Chimaera, and Heyse's adjustment for multiple comparisons. ${ }^{25}$ Wald test for individual covariates within a particular model were evaluated at the $\alpha=0.05$ level. Because of the Gaussian nature of the models, fit statistics and $R^{2}$ values were also estimated using traditional regression methods. All data were analyzed using SAS v 9.3 (SAS Institute, Inc, Cary, NC).

\section{RESULTS}

Between October 1998 and April 2003, 675 infants were eligible for cardiac surgery, with $550(81 \%)$ enrolled in the APOE study. Of these, 486 were eligible for 4-year ND evaluation, which was completed by $381(78 \%)$ subjects. The only difference in baseline characteristics between returning and nonreturning patients was underrepresentation of non-Hispanic black patients in returning patients ( $21 \%$ vs $29 \%)$. Ninety-six $(25 \%)$ patients returning for 4-year evaluation had undergone staged reconstruction for HLHS or variants and form the current study population. Baseline and clinical characteristics are summarized in Table 1.

Initial surgical intervention with $\mathrm{CPB}$ was performed on 94 patients $(98 \%)$ as neonates $(<30$ days). Details of operative management are shown in Table 2. DHCA was uniformly used for aortic arch reconstruction. All children underwent additional cardiac and/or noncardiac surgical procedures after their initial cardiac surgery, and anesthetic exposure data were evaluated for all procedures occurring at our institution up to the date of ND evaluation, with the last ND evaluation occurring in February 2008. In this subgroup of 96 patients, initial VAA exposure occurred at less than 1 year of age in all 
TABLE 1. Baseline covariates

\begin{tabular}{|c|c|c|c|}
\hline Variable & $f(\%)$ & Mean (SD) & $\begin{array}{l}\text { Median } \\
\left(Q_{1}, Q_{3}\right) \\
\end{array}$ \\
\hline Gestational age, wk & & $38.4(1.9)$ & $39.0(38.0,39.0)$ \\
\hline Birth weight, $\mathrm{kg}$ & & $3.2(0.6)$ & $3.2(2.9,3.7)$ \\
\hline \multicolumn{4}{|l|}{ Gender } \\
\hline Male & $54(56.2)$ & & \\
\hline Female & $42(43.8)$ & & \\
\hline \multicolumn{4}{|l|}{ Ethnicity } \\
\hline $\begin{array}{l}\text { Asian-Pacific, Hispanic, } \\
\text { Native American, or } \\
\text { other }\end{array}$ & $5(5.2)$ & & \\
\hline Black & $18(18.8)$ & & \\
\hline White & $73(76.0)$ & & \\
\hline \multicolumn{4}{|l|}{ Maternal education } \\
\hline Less than high school & $4(4.2)$ & & \\
\hline High school/some college & $39(41.0)$ & & \\
\hline College degree & $37(39.0)$ & & \\
\hline Graduate degree & $15(15.8)$ & & \\
\hline \multicolumn{4}{|l|}{ Socioeconomic status } \\
\hline $\begin{array}{l}\text { Unskilled laborers, menial } \\
\text { service workers }\end{array}$ & $3(3.2)$ & & \\
\hline $\begin{array}{l}\text { Machine operators, } \\
\text { semiskilled workers }\end{array}$ & $6(6.4)$ & & \\
\hline $\begin{array}{l}\text { Skilled craftsman, clerical, } \\
\text { sales workers }\end{array}$ & $21(22.3)$ & & \\
\hline $\begin{array}{l}\text { Medium business, minor } \\
\text { professional, technical }\end{array}$ & $29(30.9)$ & & \\
\hline $\begin{array}{l}\text { Major business and } \\
\text { professional }\end{array}$ & $35(37.2)$ & & \\
\hline \multicolumn{4}{|l|}{$A P O E$} \\
\hline$\varepsilon 2(\varepsilon 2 \varepsilon 2, \varepsilon 2 \varepsilon 3)$ & $12(12.5)$ & & \\
\hline$\varepsilon 3(\varepsilon 3 \varepsilon 35)$ & $55(57.3)$ & & \\
\hline$\varepsilon 4(\varepsilon 3 \varepsilon 3, \varepsilon 3 \varepsilon 4)$ & $25(26.0)$ & & \\
\hline$\varepsilon 2, \varepsilon 4$ & $4(4.2)$ & & \\
\hline
\end{tabular}

but 2 patients $(97.9 \%)$, and at less than 1 month of age in $45(46.8 \%)$. DHCA was uniformly used for aortic arch reconstruction.

Retrieval of AIMS anesthetic case-specific numbers associated with the medical record numbers of the 96 patients yielded 726 case records. Of these, 25 handwritten records could not be located for review, and in 12 additional cases anesthetic care was provided as "standby" only. Thus, 689 encounters were reviewed; anesthetic encounters per patient ranged from 1 to 26 (median 6). Cumulative exposure to VAAs ranged from 0 to 35.3 MAC-hrs (median 7.5 hours) with 95 of 96 patients exposed to VAAs. Of the 689 anesthetic records evaluated, 496 included exposures to VAAs, with $37(38.5 \%)$ of 96 patients exposed to VAAs during their initial cardiac surgery.

Among the 4 models tested, all 4 models yielded statistically significant omnibus values, suggesting a statistically significant relationship between the hypothesized covariates and each outcome. The relationship between VAA exposure and the outcomes are shown in Figure 1. However, only 2 of the 4 models (WPPSI-III FSIQ and VIQ) yielded statistically significant relationships with the covariate of interest, total MAC-hrs. The following is a summary of the results by model using the prespecified covariates identified as significant predictors by previous anal$y^{24}{ }^{24}$ (Table 3). The table provides a complete listing of parameter estimates, 95\% confidence limits, and Wald statistics for each model listed as follows. Significance levels less than the $P=.01$ were denoted as $P<.01$ for consistency (2 decimal places). All others are statistically significant terms denoted with the actual $P$ value, still maintaining 2 decimal places.

Model 1 (FSIQ) yielded a statistically significant relationship between the aforementioned covariates and WPPSI FSIQ score $\left(P<.01, R^{2}=0.34, \mathrm{n}=96\right)$. Total MAC-hrs was deemed to be statistically significant $(P=.02)$ after adjusting for the specified covariates: gestational age $(P=.02)$, CPB $(P=.06)$, hematocrit $(P<.01)$, and postoperative LOS $(P<.01)$. Comparison of nested models with and without MAC-hrs yielded a statistically significant $F_{\text {obs }}=4.58(P<.05)$ for the covariate of interest.

Model 2 (VIQ) yielded a statistically significant relationship between aforementioned covariates and WPPSI VIQ score $\left(P<.01, R^{2}=0.30, \mathrm{n}=96\right)$. Total MAC-hrs was deemed to be statistically significant $(P=.01)$ after adjusting for covariates: CPB $(P=.11)$, hematocrit $(P<.01)$ and postoperative LOS $(P<.01)$. Comparison of nested models with and without MAC-hrs yielded a statistically significant $F_{\text {obs }}=6.73(P<.05)$ for the covariate of interest.

Model 3 (PIQ) yielded a statistically significant relationship between the aforementioned covariates and WPPSI PIQ score $\left(P<.01, R^{2}=0.16, \mathrm{n}=95\right)$; however, only birth weight $(P=.04)$ and postoperative $\operatorname{LOS}(P=.04)$, were found to be statistically significant. All other terms, including total MAC-hrs $(P=.43)$ were not statistically significant.

Model 4 (Processing Speed) yielded a statistically significant relationship between the aforementioned covariates and WPPSI Processing Speed $\left(P<.01, R^{2}=0.22\right.$, $\mathrm{n}=86)$, but only gestational age $(P<.01)$ and postoperative LOS $(P=.01)$ were statistically significant. Total MAC-hrs $(P=.66)$ was not statistically significant.

\section{DISCUSSION}

This study provides evidence that in children undergoing staged reconstructive surgery for HLHS, increasing cumulative exposure to VAAs beginning in infancy is associated with worse performance for FSIQ and VIQ, suggesting that VAA exposure may be a modifiable risk factor for adverse ND outcomes. The current study has several advantages in comparison with previous studies. Study candidates belonging to a homogeneous diagnostic 
TABLE 2. Management covariates

\begin{tabular}{|c|c|c|c|}
\hline Variable & $f(\%)$ & Mean (SD) & $\operatorname{Median}\left(Q_{1}, Q_{3}\right)$ \\
\hline \multicolumn{4}{|l|}{ Operative characteristics (1st cardiac surgery) } \\
\hline Age, $\mathrm{d}$ & & $6.6(14.4)$ & $3.0(2.0,6.5)$ \\
\hline Weight, kg & & $3.3(0.8)$ & $3.2(2.8,3.7)$ \\
\hline Total CPB time, $\min$ & & $54.6(25.7)$ & $44.0(39.0,61.5)$ \\
\hline Total DHCA time, min & & $44.6(14.8)$ & $42.0(36.0,53.0)$ \\
\hline Hematocrit after hemodilution, $\%$ & & $28.8(4.0)$ & $29.0(26.0,31.0)$ \\
\hline Postoperative length of stay, $\mathrm{d}$ & & $15.9(11.6)$ & $11.0(9.0,18.0)$ \\
\hline Additional cardiac operations before 4-y evaluation & & $2.1(0.4)$ & $2.0(2.0,2.0)$ \\
\hline Total additional CPB before ND evaluation, min & & $167.5(78.9)$ & $137.5(116.5,203.5)$ \\
\hline Total additional DHCA before ND evaluation, min & & $86.7(30.5)$ & $83.5(72.0,98.0)$ \\
\hline Preoperative mechanical ventilation, y & $40(41.7 \%)$ & & \\
\hline Use of ECMO/LVAD, y & $4(4.2 \%)$ & & \\
\hline Delayed sternal closure, $\mathrm{y}$ & $18(18.8 \%)$ & & \\
\hline
\end{tabular}

$\mathrm{N}=$ 96. $S D$, Standard deviation; $Q_{1}$, first quartile, $Q_{3}$, third quartile; $C P B$, cardiopulmonary bypass; $D H C A$, deep hypothermic circulatory arrest; $N D$, neurodevelopmental; $E C M O / L V A D$, extracorporeal membrane oxygenation/left ventricular assist device.

category were identified and enrolled before initial surgery, allowing for identification and prospective data collection of both patient-related and perioperative variables. Volatile anesthetic exposure was more precisely quantified than in any previous study. Cognitive testing was performed by a dedicated team of pediatric behavioral specialists who were unaware of the anesthetic exposure, with the advantage of revealing deficits in specific domains that would perhaps not be evident solely by observations of academic performance, school records, or parental surveys. ND assessment in preschool children allows improved evaluation of higher and more complex function that does earlier assessment.
Neonates born with HLHS have a significant risk of subsequent ND disability. The multicenter Single Ventricle Reconstruction trial evaluated ND outcomes in 314 children with HLHS at a mean age of 14.31. \pm 1 months using the Bayley Scales of Infant Development- II (BSID-II), finding that patients with no recognized genetic syndrome and a birth weight heavier than $2.5 \mathrm{~kg}$ had the highest scores. Patient characteristics and measures of greater severity of illness were more highly associated with adverse ND outcomes than were medical or operative management strategies. ${ }^{7}$ Importantly, anesthetic management was not evaluated.

Animal studies have shown the developing mammalian brain is vulnerable to anesthetic-induced damage. ${ }^{26,27} \mathrm{In}$
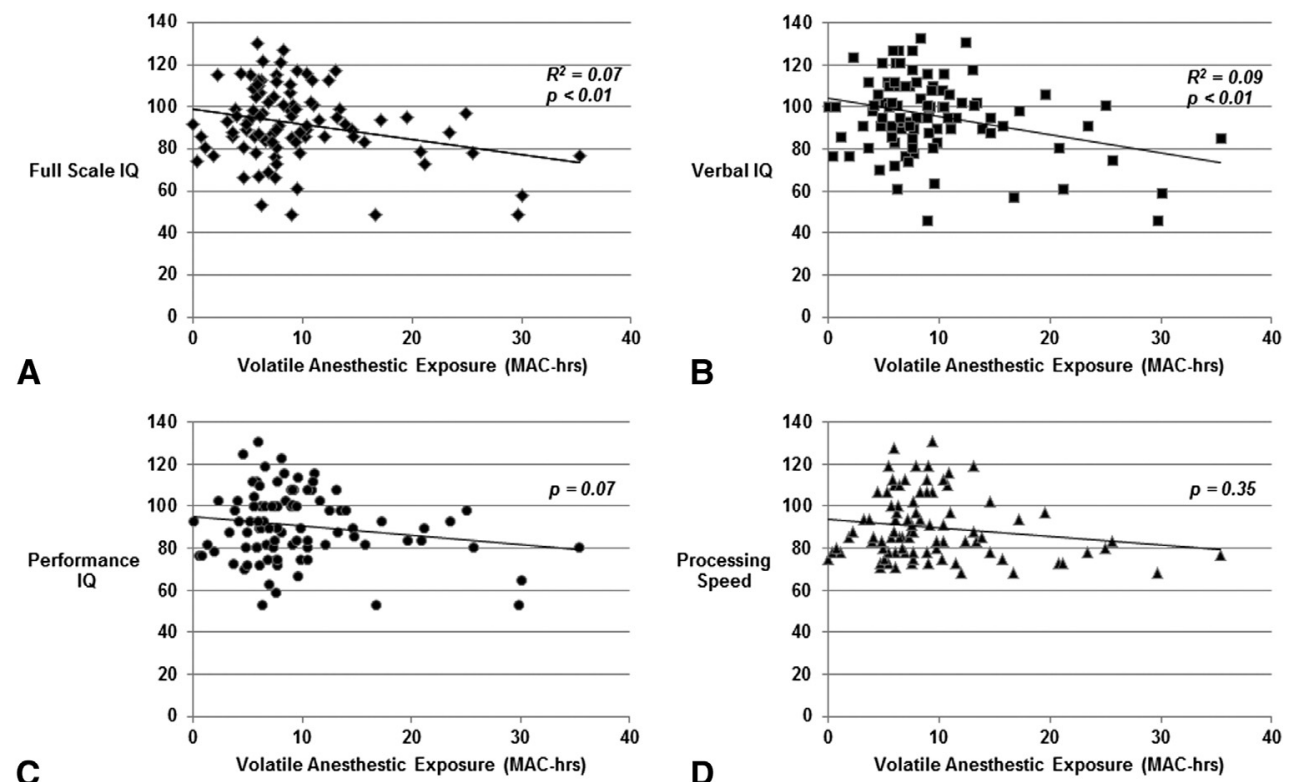

FIGURE 1. A, Relationship between cumulative VAA exposure and full-scale IQ. B, Relationship between cumulative VAA exposure and verbal IQ. C, Relationship between cumulative VAA exposure and performance IQ. D, Relationship between cumulative VAA exposure and processing speed. MAC-hrs, Minimum alveolar concentration hours. 
TABLE 3. Full-scale IQ, verbal IQ, performance IQ, and processing speed regression models

\begin{tabular}{|c|c|c|c|c|c|c|}
\hline \multicolumn{5}{|c|}{ Model } & \multicolumn{2}{|c|}{ Model } \\
\hline Covariate & $\beta$ & $S E$ & $95 \%$ CL & $P$ & $P$ & $R^{2}$ \\
\hline Model 1: Full-Scale IQ & & & & & $<.01$ & 0.34 \\
\hline Total MAC-hrs & -0.53 & 0.24 & $(-1.00,-0.07)$ & .02 & & \\
\hline Gestational age & 1.88 & 0.80 & $(0.32,3.44)$ & .02 & & \\
\hline $\mathrm{CPB}$ & -0.04 & 0.02 & $(-0.07,0.00)$ & .06 & & \\
\hline Hematocrit & 1.18 & 0.37 & $(0.46,1.90)$ & $<.01$ & & \\
\hline Postop LOS & -0.41 & 0.13 & $(-0.67,-0.15)$ & $<.01$ & & \\
\hline Intercept & 3.46 & 33.94 & $(-63.06,69.98)$ & & & \\
\hline Model 2: Verbal IQ & & & & & $<.01$ & 0.30 \\
\hline Total MAC-hrs & -0.67 & 0.25 & $(-1.17,-0.18)$ & .01 & & \\
\hline $\mathrm{CPB}$ & -0.03 & 0.02 & $(-0.07,0.01)$ & .11 & & \\
\hline Hematocrit & 1.19 & 0.39 & $(0.42,1.96)$ & $<.01$ & & \\
\hline Postop LOS & -0.46 & 0.14 & $(-0.72,-0.19)$ & $<.01$ & & \\
\hline Intercept & 80.90 & 12.50 & $(56.41,105.39)$ & & & \\
\hline Model 3: Performance IQ & & & & & $<.01$ & 0.16 \\
\hline Total MAC-hrs & -0.20 & 0.25 & $(-0.68,0.29)$ & .43 & & \\
\hline Birth weight & 5.27 & 2.62 & $(0.15,10.40)$ & .04 & & \\
\hline $\mathrm{CPB}$ & -0.03 & 0.02 & $(-0.08,0.01)$ & .10 & & \\
\hline Postop LOS & -0.30 & 0.14 & $(-0.58,-0.02)$ & .04 & & \\
\hline Intercept & 86.36 & 10.14 & $(66.49,106.23)$ & & & \\
\hline Model 4: Processing Speed & & & & & $<.01$ & 0.22 \\
\hline Total MAC-hrs (ln) & $-9.44 e-6$ & $2.15 \mathrm{e}-5$ & $(-5.22 \mathrm{e}-5,3.33 \mathrm{e}-5)$ & .66 & & \\
\hline Gestational age & $-5.38 \mathrm{e}-5$ & $1.70 \mathrm{e}-5$ & $(-8.76 e-5,-1.99 e-5)$ & $<.01$ & & \\
\hline Postop LOS & $6.34 \mathrm{e}-6$ & $2.53 \mathrm{e}-6$ & $(1.31 \mathrm{e}-6,1.14 \mathrm{e}-5)$ & .01 & & \\
\hline Intercept & $3.08 \mathrm{e}-3$ & $6.63 \mathrm{e}-4$ & $(1.76 e-3,4.40 e-3)$ & & & \\
\hline
\end{tabular}

MAC-hrs, Minimum alveolar concentration hours; $C P B$, cardiopulmonary bypass; Postop LOS, postoperative length of stay.

humans, the neonatal period corresponds with the period of greatest vulnerability to anesthetic exposure. ${ }^{28}$ Although some studies have included patients exposed to GA at younger than 1 year, most studies have examined patients who received GA closer to 2 to 3 years of age. . $^{13,14,29,30}$ Most of our patients were initially exposed to GA, including VAAs, at younger than 6 months $(81.2 \%)$, with $45(46.8 \%)$ of 96 exposed as neonates. Additionally, we documented repeated anesthetic exposure in all but 1 subject. Recent cohort studies have evaluated exposure to GA during infancy or early childhood in children. Block et $\mathrm{al}^{29}$ examined 158 patients anesthetized at younger than 1 year, with a subgroup of patients identified as having no preexisting CNS problems. In both groups, a higher proportion of children performed below the fifth percentile in state achievement tests compared with unexposed children. However, anesthetic drug exposure was provided only for the subgroup, without exposure quantification. In a matched cohort of 350 patients exposed to GA before age 2 years, Flick et $\mathrm{al}^{30}$ found multiple anesthetic/surgical exposures significantly increased the risk for development of learning disabilities even after adjusting for health status. Most patients received halothane and nitrous oxide as the primary anesthetic, with no precise information available regarding exposure. ${ }^{30}$ Although some of our patients received halothane, most of the exposure in our cohort was to isoflurane, making our results more applicable to current practice.

Several studies have attempted to examine possible effects of early anesthetic exposure in infants with CHD. Guerra and colleagues ${ }^{14}$ examined a heterogeneous population of 95 children with CHD who underwent cardiac surgery at younger than 6 weeks, 24\% with a diagnosis of HLHS. Anesthetic/sedative data between birth and age 6 weeks were collected retrospectively from chart review. Additional anesthetic exposures between age 6 months and ND testing were not evaluated. Initial ND assessment was performed between 18 and 24 months of age, but different evaluations (BSID-II and Bayley Scales of Infant and Toddler Development-III [Bayley-III]) were used for patient assessment, ${ }^{23}$ complicating outcome assessment. No association between dose and duration of sedative/analgesic drug exposure and adverse ND outcomes was found. The same population $(\mathrm{n}=91)$ was reevaluated at 4 years of age by using the WPPSI-III for FSIQ, PIQ, and VIQ, the Beery-Buktenica Developmental Test of Visual Motor Integration (VMI) and Adaptive Behavior Assessment System at the patient's respective referral institutions. Small but statistically significant correlations were identified between days of exposure to chloral hydrate and PIQ, and cumulative benzodiazepine exposure with lower VMI score. No 
associations were found between sedation/anesthesia variables and FSIQ, PIQ, VIQ or VMI scores. ${ }^{31}$

Andropoulos et $\mathrm{al}^{13}$ followed 30 patients who underwent arterial switch operation as neonates, 20 of whom were evaluated at 12 months of age with the Bayley-III. During the initial cardiac surgery, isoflurane exposure was calculated in 15-minute increments, whereas intensive care unit (ICU) medications were noted for the first 72 hours postoperatively. For the 20 patients who underwent ND testing, only 0 to 1 additional anesthetic exposure was recorded in the first 12 months. An association was described between larger total midazolam doses and lower Language and Motor scores, and larger total fentanyl doses were associated with higher Cognitive scores. Subsequently Andropoulos and colleagues ${ }^{32}$ reported a retrospective cohort of 59 neonates with complex CHD who underwent surgery with $\mathrm{CPB}$ within the first 30 days of life. Perioperative anesthetic and sedative data for the initial intraoperative exposure and the subsequent 72 hours were collected, and retrospective chart review was used to collect volatile and intravenous anesthetic exposure in the first year of life. VAA data were collected from both handwritten and electronic records at 5- and 15-minute intervals. A consistent association was identified between longer ICU LOS and lower Bayley-III scores, and additionally, increasing VAA exposure was significantly associated with lower Cognitive scores. $^{32}$

\section{Limitations}

Study limitations include retrospective assessment of anesthetic exposure and limitations related to collection of volatile anesthetic exposure. Automated recordkeeping allowed VAA data capture every 2 minutes at a minimum, with capture every 15 seconds after 2003. However, anesthetic exposure may have been underestimated in some patients. In off-site venues without AIMS, VAA administration data documented via handwritten record was not included due to its relative inaccuracy compared with automated records. Similarly, for cases using CPB, VAA was frequently administered during $\mathrm{CPB}$ via a vaporizer in the bypass circuit. At the time of the study, perfusion records did not reflect VAA administration; however, even if VAA had been noted, accurate estimation of VAA exposure comparable with our other data would not have been possible. Most importantly, we were only able to analyze anesthetic exposure for procedures occurring at our institution. Some children had procedures performed at other institutions, and the number of these procedures and the resultant anesthetic exposure is not known.

Longer hospital LOS and the need for additional cardiac operations during the first year of life have been correlated with worse ND outcomes in the patient cohort. ${ }^{7,33}$ Children with a longer LOS are also more likely to have undergone additional surgeries or procedures requiring increased exposure to anesthetic or sedative drugs. We have attempted to control for this by adjusting for both LOS after Stage I palliation (Norwood procedure), which is likely to be the child's longest hospitalization, and number of cardiac operations. Finally, the potential exists that certain VAA exposures could confer neuroprotective effects. $^{34}$

\section{CONCLUSIONS}

This study demonstrates cumulative VAA exposure with initial volatile anesthetic exposure for neonates with HLHS and extending to 4 to 5 years of life, with standardized comprehensive ND assessment at that time. After adjusting for multiple covariates previously demonstrated to influence ND outcomes, we demonstrated that greater exposure to VAAs is correlated with worse outcomes in both FSIQ and VIQ scores. Although important, these findings are preliminary and cannot yet justify changing current practice. Nonmodifiable patient-specific factors have been shown to contribute to ND outcomes, but modifiable factors such as anesthetic and sedative exposure must be further examined in order to improve outcomes and quality of life of survivors with $\mathrm{CHD}$. Prospective randomized controlled multicenter clinical trials are indicated to continue to clarify the effects of early and repetitive exposure to VAA in this and other pediatric populations.

\section{Conflict of Interest Statement}

Authors have nothing to disclose with regard to commercial support.

\section{References}

1. Lloyd-Jones D. Heart disease and stroke statistics: a 2010 update. Circulation. 2010;121:e46-121.

2. Hovels-Gurich HH, Bauer SB, Schnitker R, Willmes-von Hinckeldey K, Messmer BJ, Seghaye M-C, et al. Long-term outcome of speech and language in children after corrective surgery for cyanotic or acyanotic cardiac defects in infancy. Eur J Paediatr Neurol. 2008;12:378-86.

3. Licht DJ, Shera DM, Clancy RR, Wernovsky G, Montenegro LM, Nicolson SC, et al. Brain maturation is delayed in infants with complex congenital heart defects. J Thorac Cardiovasc Surg. 2009;137:529-36; discussion 536-7.

4. McQuillen PS, Goff DA, Licht DJ. Effects on congenital heart disease on brain development. Prog Pediatr Cardiol. 2010;29:79-85.

5. Bellinger D, Newberger JA. Neuropsychological, psychosocial, and quality-oflife outcomes in children and adolescents with congenital heart disease. Prog Pediatr Cardiol. 2010;29:87-92.

6. Gaynor JW, Wernovsky G, Jarvik GP, Bernbaum J, Gerdes M, Zackai E, et al. Patient characteristics are important determinants of neurodevelopmental outcome at one year of age after neonatal and infant cardiac surgery. $J$ Thorac Cardiovasc Surg. 2007;133:1344-53.

7. Newburger JW, Sleeper LA, Bellinger DC, Goldberg CS, Tabbutt S, Lu M, et al. Early developmental outcome in children with hypoplastic left heart syndrome and related anomalies: the single ventricle reconstruction trial. Circulation. 2012;125:2081-91.

8. Tabbutt S, Nord AS, Jarvik GP, Bernbaum J, Wernovsky G, Gerdes M, et al. Neurodevelopmental outcomes after staged palliation for hypoplastic left heart syndrome. Pediatrics. 2008;121:476-83. 
9. Brambrink AM, Evers AS, Avidan MS, Farber NB, Smith DJ, Zhang X, et al. Isoflurane-induced neuroapoptosis in the neonatal rhesus macaque brain. Anesthesiology. 2010;112:834-41.

10. Brambrink AM, Orfanakis A, Kirsch JR. Anesthetic neurotoxicity. Anesthesiol Clin. 2012;30:207-28.

11. DiMaggio C, Sun LS, Li G. Early childhood exposure to anesthesia and risk of developmental and behavioral disorders in a sibling birth cohort. Anesth Analg. 2011;113:1143-51.

12. Ing C, DiMaggio C, Whitehouse A, Hegarty MK, Brady J, von UngernSternberg BS, et al. Long-term differences in language and cognitive function after childhood exposure to anesthesia. Pediatrics. 2012;130: e476-85.

13. Andropoulos DB, Easley RB, Brady K, McKenzie ED, Heinle JS, Dickerson HA, et al. Changing expectations for neurological outcomes after the neonatal arterial switch operation. Ann Thorac Surg. 2012;94:1250-5; discussion 1255-6.

14. Guerra GG, Robertson CM, Alton GY, Joffe AR, Cave DA, Dinu IA, et al. Neurodevelopmental outcome following exposure to sedative and analgesic drugs for complex cardiac surgery in infancy. Paediatr Anaesth. 2011;21:932-41.

15. Gaynor JW, Ittenbach RF, Gerdes M, Bernbaum J, Clancy RR, McDonaldMcGinn DM, et al. Neurodevelopmental outcomes in preschool survivors of the fontan procedure. J Thorac Cardiovasc Surg. 2014;147:1276-82; discussion 1282-3.e5.

16. Gaynor JW, Gerdes M, Zackai EH, Bernbaum J, Wernovsky G, Clancy RR, et al. Apolipoprotein e genotype and neurodevelopmental sequelae of infant cardiac surgery. J Thorac Cardiovasc Surg. 2003;126:1736-45.

17. Yasuda N, Lockhart SH, Eger EI II, Weiskopf RB, Johnson BH, Freire BA, et al. Kinetics of desflurane, isoflurane, and halothane in humans. Anesthesiology. 1991;74:489-98.

18. Yasuda N, Lockhart SH, Eger EI II, Weiskopf RB, Liu J, Laster M, et al. Comparison of kinetics of sevoflurane and isoflurane in humans. Anesth Analg. 1991;72:316-24.

19. Bailey JM. Context-sensitive half-times: what are they and how valuable are they in anaesthesiology? Clin Pharmacokinet. 2002;41:793-9.

20. Cameron CB, Robinson S, Gregory GA. The minimum anesthetic concentration of isoflurane in children. Anesth Analg. 1984;63:418-20.

21. Lerman J, Sikich N, Kleinman S, Yentis S. The pharmacology of sevoflurane in infants and children. Anesthesiology. 1994;80:814-24.

22. Taylor RH, Lerman J. Minimum alveolar concentration of desflurane and hemodynamic responses in neonates, infants, and children. Anesthesiology. 1991;75: 975-9.
23. Hollingshead A. Four Factor Index of Social Status [unpublished manuscript] New Haven, CT: Yale University; 1975.

24. Wechsler D. Wechsler Preschool and Primary Scale of Intelligence-3rd Edition San Antonio, TX: Harcourt Assessment Company; 2002.

25. Zhang J, Quan H, Ng J, Stepanavage ME. Some statistical methods for multiple endpoints in clinical trials. Control Clin Trials. 1997;18:204-21.

26. Rizzi S, Ori C, Jevtovic-Todorovic V. Timing versus duration: determinants of anesthesia-induced developmental apoptosis in the young mammalian brain. Ann N Y Acad Sci. 2010;1199:43-51.

27. Rizzi S, Carter LB, Ori C, Jevtovic-Todorovic V. Clinical anesthesia causes permanent damage to the fetal guinea pig brain. Brain Pathol. 2008;18: 198-210.

28. Clancy B, Finlay BL, Darlington RB, Anand KJ. Extrapolating brain devel opment from experimental species to humans. Neurotoxicology. 2007;28: 931-7.

29. Block RI, Thomas JJ, Bayman EO, Choi JY, Kimble KK, Todd MM. Are anesthesia and surgery during infancy associated with altered academic performance during childhood? Anesthesiology. 2012;117:494-503.

30. Flick RP, Katusic SK, Colligan RC, Wilder RT, Voigt RG, Olson MD, et al Cognitive and behavioral outcomes after early exposure to anesthesia and surgery. Pediatrics. 2011;128:e1053-61.

31. Garcia Guerra G, Robertson CM, Alton GY, Joffe AR, Cave DA, Yasmin F, et al. Neurotoxicity of sedative and analgesia drugs in young infants with congenital heart disease: 4-year follow-up. Paediatr Anaesth. 2014;24: 257-65.

32. Andropoulos DB, Ahmad HB, Haq T, Brady K, Stayer SA, Meador MR, et al The association between brain injury, perioperative anesthetic exposure, and 12-month neurodevelopmental outcomes after neonatal cardiac surgery: a retrospective cohort study. Paediatr Anaesth. 2014;24:266-74.

33. Fuller S, Nord AS, Gerdes M, Wernovsky G, Jarvik GP, Bernbaum J, et al. Predictors of impaired neurodevelopmental outcomes at one year of age after infant cardiac surgery. Eur J Cardiothorac Surg. 2009;36: 40-7.

34. McAuliffe JJ, Loepke AW, Miles L, Joseph B, Hughes E, Vorhees CV. Desflurane, isoflurane, and sevoflurane provide limited neuroprotection against neonatal hypoxia-ischemia in a delayed preconditioning paradigm. Anesthesiology. 2009; 111:533-46.

Key Words: congenital heart surgery, anesthesia, neurotoxicity, neurodevelopment 